\title{
Logistiek: Die oorsprong, konsep- tuele ontwikkeling en betekenis daarvan in hedendaagse gebruik
}

Wessel J. Pienaar, Departement Logistiek, Universiteit van Stellenbosch, Stellenbosch, Republiekvan Suid-Afrika (wpienaar@sun.ac.za)

Opsomming: Hierdie artikel beskryf die oorsprong van die woord logistiek, stip die ontwikkeling daarvan uit en verklaar die hedendaagse betekenis daarvan. Die ontwikkelingsgang van die begrip word aangedui vanaf die oorsprong daarvan in Grieks, met inagneming van die opeenvolgende opname daarvan in Laat-Latyn, Frans en Nederlands, tot by die huidige gebruik daarvan in Afrikaans. Die vestiging van die Franse logistique as militêre konsep gedurende die Napoleontiese oorloë, en die uitbreiding daarvan tot 'n bedryfsbegrip ná afloop van die Tweede Wêreldoor$\log$ word verduidelik. Die ontwikkelingsgang sedertdien van die betekenis van die konsep in bedryfsverband word bespreek. Eietydse omskrywings van logistiek, betreffende die gebruik daarvan in die bedryfslewe en in die omgangstaal, word verskaf. Vervolgens bied die artikel 'n eietydse definisie van logistiek in bedryfsverband. Ten slotte word aangetoon hoe doeltreffende bedryfslogistiek waarde toevoeg.

Sleutelwoorde: BEDRYFSLOGISTIEK, BESITNUT, BESTUUR, DIENS, DOELMATIGHEID, DOELTREFFENDHEID, GOEDERE, GRONDSTOF, INLIGTING, KLIËNTEDIENS, KLIËNTETEVREDENHEID, LOGISTIEK, MILITÊRE LOGISTIEK, NUT, PLEKNUT, PRODUK, TYDNUT, VORMNUT, WAARDE

\begin{abstract}
Logistics: Its Origin, Conceptual Evolution and Meaning in Contemporary Usage. This article traces the origin of the word logistics, outlines its conceptual evolution, and explains its meaning in contemporary usage. The contextual development of the concept is traced from its origin in Greek, along with its successive adoption in Late Latin, French and Dutch, up to its contemporary usage in Afrikaans. The establishment of the French logistique as military concept during the Napoleonic wars, and its later extension to commercial usage subsequent to the Second World War are described. The development since then of the meaning of the concept in a commercial context is detailed. Contemporary descriptions of logistics relating to its meaning in a commercial sense and in common parlance are discussed. Thereafter the article offers a contemporary definition of logistics in a commercial context. Finally it is indicated how effective business logistics adds value.
\end{abstract}

Keywords: BUSINESS LOGISTICS, CUSTOMER SATISFACTION, CUSTOMER SERVICE, EFFECTIVENESS, EFFICIENCY, FORM UTILITY, GOODS, INFORMATION, LOGISTICS, MANAGEMENT, MILITARY LOGISTICS, PLACE UTILITY, POSSESSION UTILITY, PRODUCT, RESOURCE, SERVICE, TIME UTILITY, UTILITY, VALUE 


\section{Inleiding}

Die woord logistiek word toenemend in die algemene omgangstaal en in die bedryfslewe gebruik. In die omgangstaal verwys logistiek gewoonlik na die poging om 'n ingewikkelde gebeurtenis vlot te laat verloop. In 'n bedryfskonteks verwys dit na die proses om grondstowwe vanaf hul oorsprong te verplaas, die omvorming daarvan te ondersteun en die voltooide produkte op die regte plek en tyd vir verbruik beskikbaar te stel.

Die doel van hierdie artikel is om die oorsprong van die woord logistiek na te speur, die konseptuele ontwikkeling daarvan uit te stip en die betekenis daarvan in hedendaagse gebruik te verklaar.

\section{Evolusie van die begrip logistiek}

Die woord logistiek is afgelei van die Griekse byvoeglike naamwoord logistikos, wat beteken "geskool in berekening", "met verwysing na rekenkunde" of "wat gemoeid is met rede". Die byvoeglike naamwoord is afgelei van die werkwoord logizomai, wat volgens die konteks beteken "om te bereken", "om te redeneer" of "om te dink". Die werkwoord is gegrond op die woord logos, wat vertaal word as rede, woord of gesprek. Die Grieke het die lede van 'n mediese skool wat rede en mediese praktyk gekombineer het, logistikoi genoem.

Die Griekse logistikos het die Europese hooftale deur die Laat-Latynse logisticus bereik, wat logistique in Frans geword het. Die selfstandige naamwoord logistique het sedert 1546 begin verskyn. In Discours du songe de Poliphile (Gesprek oor Polifilus se droom), wat in 1593 gepubliseer is, word rede verteenwoordig deur 'n persoon genaamd Logistique (hy wat redeneer) (Boucher 1998: 1). In 1611 is die selfstandige naamwoord logistique met verwysing na die vier prosesse van rekenkunde en algebra (optel, aftrek, maal en deel) gebruik. In 1765 is die byvoeglike naamwoord logistique wat "met verwysing na berekening" beteken, van hierdie naamwoord afgelei. Hierdie twee betekenisse het grotendeels in onbruik geraak (Dictionnaires Le Robert 1976: 1004). (Dieselfde het gebeur met logarithmes logistiques (logistiese logaritmes), waar die logaritme van 3600 as gelyk aan nul beskou is ten einde sekere berekeninge wat met sterrekundige waarnemings verband hou, te vereenvoudig.)

Die gebruik van die woord logistique vir die vermoë om die inkwartiering, vervoer, voorsiening en onderhoud van troepe tydens 'n militêre veldtog te kombineer en koördineer deur beredenering gegrond op berekeninge, word toegeskryf aan Antoine Henri, Baron van Jomini. Jomini was 'n militêre teoretikus wat as brigadier-generaal in Napoleon se leër gedien het. Hy het die woord in 1836 in hierdie konteks bekend gestel in sy hoogs invloedryke werk Précis de l'art de la guerre (Opsomming van die krygskuns) (Parkinson 1977: 90; Macksey en Woodhouse 1991: 198), soos dit in 1840 deur die Franse Akademie erken is (Dictionnaires Le Robert 1996: 1299).

Die Franse logistique, met die betekenis soos deur Jomini gebruik, het 
sedert 1855 as logistiek in Nederlands begin verskyn (Van Veen en Van der Sijs 1997: 518). In 'n laat negentiende-eeuse Nederlandse werk Handboek van Vreemde Woorden, Uitdrukkingen enz. (Baale en Baale s.j.: 629) word logistiek omskryf as: "vr., letterrekening = Algebra, ook onderdeel der krijgskunde, dat den tijd en de plaats welke voor de uitvoering eener tactische beweging noodig zijn, leert berekenen." Van Dale se Groot Woordenboek der Nederlandse Taal (1984'11: 1596) se verwoording van logistiek onderskei drie punte in Jomini se geheelbeeld van die begrip: "1. (thans w.g.) wetenschap van de deductie, geformaliseerde of mathematische logica; 2. (milit.) alle voorbereidingen en handelingen die nodig zijn om de troepen op de meest doeltreffende wijze van goederen en voorraden te voorzien en onder de gunstigste omstandigheden te doen strijden; - ook deze voorziening zelf; 3 . beheersingsproces van goederenbewegingen."

Die woord logistiek het ná afloop van die Tweede Wêreldoorlog in SuidAfrika begin posvat, waarskynlik as gevolg van die intensiewe logistieke poging wat daardie oorlog geverg het en Suid-Afrika se betrokkenheid daarby. Die vroegste gebruik van logistiek in Afrikaans soos aangehaal in die Woordeboek van die Afrikaanse Taal (WAT) (1994: 348) lui soos volg: "Die maneuvers is bedoel as 'n toets vir die leër se taktiek en logistiek" (Die Burger, 16 April 1949: 3). (Die Tweede Wêreldoorlog het van 1939 tot 1945 geduur.)

Die Verklarende Handwoordeboek van die Afrikaanse Taal (Odendal 19943: 625) se verklaring van logistiek is ooglopend gegrond op punte 1 en 2 van Van Dale se verklaring daarvan: "1. (mil.) Wetenskap wat hom besighou met beplanning, ten uitvoerbringing, berekening van veral militêre aksies, voorsiening van voorrade op die doeltreffendste wyse sodat troepe onder gunstige omstandighede kan veg; berekening i.v.m. die verplasing en inkwartiering van troepe. 2. Wetenskap van die deduksie." Die WAT (1994: 348) verklaar logistiek soos volg: "1.a. (krygskunde) Gesamentlike voorbereidings en handelinge gerig op die beweging en onderhoud van krygsmagte, asook die wetenskap onderliggend hieraan. b. Alle aspekte rakende die beplanning en totstandbrenging van 'n bep. onderneming. 2. (filosofie) Simboliese logika." (Punt $1 \mathrm{~b}$ se gegewe dui eksplisiet daarop dat logistiek ook 'n niemilitêre betekenis het.)

Hoewel laasgenoemde twee omskrywings in woordeboeke van 1994 verskyn, verwoord hulle gevestigde opvattings van logistiek. Plowman (1964: 1) het reeds opgemerk (skrywer se vertaling):

Logistiek beteken, in die militêre wetenskap, die voorbereiding, hantering en organisering van personeel, ook die relevante materiaal, fasiliteite en ander faktore. Logistiek beteken dus die beredenering, veral wiskundige ontleding en sintese, van die ingewikkelde en onderling verwante probleme om personeel, voorrade en huisvesting te koördineer. Militêre logistiek is 'n oorwegende faktor ten einde dit vir 'n leër moontlik te maak om opmarse te loods, te veg en veldslae te wen. Aldus gedefinieer behels militêre logistiek die onderling verwante en hoofsaaklik wiskundige prosedures, en die gevolglik gekoördineerde besluite. 


\section{Voorkoms van logistiek in 'n bedryfskonteks}

Die verwoesting wat tydens die Tweede Wêreldoorlog in Wes-Europa aangerig is, het daartoe gelei dat Jomini se nalatenskap van militêre logistiek later as bedryfslogistiek bekend geword het. Daardie oorlog het groot gedeeltes van Wes-Europa se infrastruktuur en fisiese kapitaalvoorraad kreupel gelaat. Ook was groot gebiede plaasgrond wat tydens die oorlog die rol van slagvelde vervul het, nie geredelik vir landboudoeleindes beskikbaar nie.

Ná afloop van die vyandelikhede in 1945 het die ekonomiese heropbou van Wes-Europa begin. Deskundiges vanuit die militêre logistieke veld, wie se toewyding nie meer vir oorlogvoering benodig was nie, is in hierdie heropbouen herlewingsproses benut. Die lande betrokke in hierdie streekspoging was België, Wes-Duitsland, Frankryk, Italië, Luxemburg en Nederland.

Die herstelpoging was intensief en gekoördineerd. Dit is as noodsaaklik geag dat primêre produksie, sekondêre vervaardiging, sowel as tersiêre dienslewering spoedig op dreef moes kom ten einde ekonomiese selfbeskikking te herwin. Die herstel van, en selfs verbetering op vorige standaarde van plaaslike en tussenstreekse toeganklikheid en mobiliteit het voorrang gekry, aangesien dit duidelik was dat Wes-Europa se herlewing ten beste gedien sou word deur samewerking, streekspesialisasie, intrastreekse grondstofverkryging en die skep van 'n gemeenskapsmark. Die katalisator waardeur dit bereik kon word, was die inwerkingstelling van 'n doeltreffende logistieke stelsel, geskoei op die militêre model. Binne die streek het logistieke voorsieningskettings ontstaan asof daar geen internasionale grense was nie.

Bogenoemde ses lande het die Europese Gemeenskap (EG) as 'n streeksorganisasie in 1958 met die Ooreenkoms van Rome gestig. Die ooreenkoms het voorsiening gemaak vir die geleidelike opheffing van doeaneheffings en ander handelsbeperkings binne die EG-gebied, die skep van gemeenskaplike eksterne tariewe vir ander lande, die geleidelike invoer van 'n gemeenskaplike landboubeleid, asook waarborge vir die vrye beweging van arbeid, kapitaal en grondstowwe (Hinkelman 20004: 75). Teen hierdie tyd het gekoördineerde logistieke praktyk reeds posgevat in Wes-Europa. Die strategie om logistieke voorsieningskettings tot stand te bring wat primêre produksiepunte binne spesialiseringstreke op gekoördineerde wyse met plekke van verbruik en finale aanwending verbind het, is deeglik begryp.

Die Franse Akademie het die gebruik van logistiek in bedryfsverband (naas die militêre betekenis) in 1960 erken en het dit soos volg gedefinieer: "Ensemble de moyens et de méthodes concernant l'organisation d'un service, d'une entreprise et spécialement les flux de matières avant, pendant et après une production" (Alle wyses en metodes van die organisasie van 'n diens, 'n onderneming en veral die vloei van materiale voor, tydens en ná produksie) (Dictionnaires Le Robert 1996: 1299).

Die eerste handboek buite Europa wat die voordele van gekoördineerde bedryfslogistieke bestuur voorgehou het, het in 1961 verskyn. Dit verduidelik 
gedeeltelik waarom ' $n$ algemeen aanvaarde definisie van bedryfslogistiek toe nog in 'n vormingsproses was (Smykay, Bowersox en Mossman 1961). (Ofskoon hierdie werk primêr gerig is op fisiese distribusiebestuur, dit wil sê op die vloei van produkte vanaf vervaardiging tot by die plek van verbruik of aanwending, het dit ook na die vloei tussen die grondstofbron en produkvervaardiging verwys, wat kennelik op die Franse uitleg van bedryfslogistiek gegrond is.)

K.M. Ruppenthal, Direkteur van die First Annual Business Logistics Forum wat in 1962 by die Stanforduniversiteit plaasgevind het, het die eerste omvattende oorsig van bedryfslogistiek gepubliseer. Hy (Ruppenthal 1963: xiv) skryf soos volg (skrywer se vertaling):

Geen knap militêre aanvoerder sal daarvan droom om 'n offensief te loods indien hy nie redelik verseker is van logistieke steun nie. Die verantwoordelike generaal moet weet dat voorrade in voldoende hoeveelheid gelewer sal word en dat dit beskikbaar sal wees waar en wanneer dit benodig word. Hierdie belangrike kenmerk van beskikbaarheid is lank reeds bekend as logistiek - die fisiese verplasing van materiaal en voorraad van die verskaffingsbron tot by die plek van uiteindelike verbruik.

Ook in die bedryfslewe is die logistieke funksie die noodsaaklike skakel — in hierdie geval tussen produksie en bemarking. Bedryfslogistiek is gemoeid met die inwaartse beweging van materiaal en voorraad en die uitwaartse beweging van voltooide produkte. Die doel daarvan is die aflewering van die voltooide produkte, soos deur die bemarkingsdepartement versoek, by die punt waar dit benodig word, wanneer dit benodig word, asook op die mees ekonomiese wyse.

Dit is dus voor die hand liggend dat bedryfslogistiek meer as bloot die invul van vragbriewe, keuse van karweiers en die monitering van goederebewegings behels. Dit het ook met ' $n$ aantal ander sake te make wat inbreuk maak op doelmatige beweging en die koste daarvan:

1. Aspekte van aanlegvestiging soos dit verband hou met die beskikbaarheid, koste en algemene doelmatigheid van vervoer.

2. Pakhuiskwessies in verband met vervoer.

3. Keuse van die beste vervoermodus vir spesifieke karweiwerk.

4. Kwessies van vraggeld en tariefvasstelling.

5. Optimale besendingsgroottes, met deeglike inagneming van die produksie- en bemarkingsafdelings se behoeftes.

6. Voorraadbeleid, soos dit met vervoer verband hou.

7. Verpakkingsoorwegings, soos dit met vervoer verband hou.

8. Kwessies rakende beroepsvervoer, bruikhuur van voertuie en eie vervoer.

9. Wetgewing, regulering en ander beleidsaspekte wat vervoeraangeleenthede raak. 
10. Aanwending van ekonomiese en statistiese tegnieke vir vervoerprobleme.

11. Proefneming, navorsing en ontwikkeling afgestem op die sentrale logistieke funksie.

Dit sal niemand verbaas dat hierdie lys feitlik elke aspek van die sakeonderneming beliggaam nie. Geen hedendaagse sakeonderneming kan bekostig om in netjiese kompartemente verdeel te word nie; in der waarheid is alle departemente verwant. Dit is hierdie verwantskap tussen die departemente van hedendaagse sakeondernemings wat die terrein van die bedryfslogistiek bepaal.

Om bedryfslogistiek te ignoreer, om die ondeelbare aard van die hedendaagse sakeonderneming mis te kyk, is om ondergang te bewerkstellig aldus Ruppenthal. Ná Ruppenthal se weergawe van bedryfslogistiek in 1962 het omskrywings van logistiek in bedryfsverband nog 'n kwarteeu lank op die vloei van goedere gefokus. Dit was eers gedurende die laat jare tagtig dat daar in die literatuur ook na die belangrikheid van inligting- en dienstevloei verwys is. In 1986 het die Council of Logistics Management (CLM), die grootste logistieke beroepsliggaam in die VSA, logistiek gedefinieer as (skrywer se vertaling) "die proses van beplanning, implementering en beheer van die doelmatige, kostedoeltreffende vloei en opberging van grondstowwe, halfvoltooide produkte, voltooide produkte en verwante inligting vanaf die plek van oorsprong tot die plek van verbruik met die doel om aan kliëntevereistes te voldoen" (CLM 1986: 2). In 1987 is die heersende opvatting van bedryfslogistiek deur Ballou (19872) so weergegee: "Bedryfslogistiek dek alle beweging en opbergingsaktiwiteite wat produkvloei vanaf 'n plek van grondstofverkryging tot by die plek van finale verbruik fasiliteer, sowel as die inligtingvloei wat die produk in beweging stel, met die doel om voldoende vlakke van kliëntediens teen billike koste te voorsien." (Let daarop dat produkte goedere of dienste kan wees.)

Routledge se Concise Dictionary of Management (Statt 1991: 81) erken die feit dat die term logistiek posgevat het in die Engelse sakewoordeskat deur dit te omskryf as "a term that was originally used in the military to describe the organizing and moving of troops and equipment". Dit sê voorts: "It is now often applied to any detailed planning process in an organization which entails the distribution or redistribution of resources." In ooreenstemming hiermee en samehangend met die Franse Akademie se verklaring van die begrip (Dictionnaires Le Robert 1996: 1299) omskryf die Oxford Dictionary for the Business World (1993: 485) logistiek as "1 organization of (orig. military) services and supplies. 2 control of the movement of materials in a factory, from the arrival of raw materials to the packaging of the product, known as materials management, together with distribution management (or marketing logistics), which includes the storage of goods and their distribution to distributors and consumers. 3 organization of any complex operation". In 1995 gee die Cambridge International Dictionary of English (1995: 837) gelyke erkenning aan die term 
logistiek in militêre en sakeverband deur dit te verklaar as "the careful organization of a complicated military or business activity so that it happens in a successful and effective way".

In 1991 het die CLM erkenning verleen aan die belangrikheid van dienstevloei en sy definisie van logistiek (skrywer se vertaling) gewysig na: "die proses van beplanning, implementering en beheer van die doelmatige, doeltreffende vloei en opberging van goedere, dienste en verwante inligting vanaf die plek van oorsprong tot by die plek van verbruik met die doel om aan kliëntevereistes te voldoen." Die CLM (1991: 4) beklemtoon dat hierdie definisie inwaartse, uitwaartse, interne en eksterne verplasing, sowel as goedereretoere ter wille van omgewingsdoeleindes insluit.

In 1998 het die CLM hierdie definisie soos volg herbewoord (skrywer se vertaling): "Logistiek is daardie deel van die voorsieningskettingproses wat gemoeid is met die beplanning, implementering, en beheer van die doelmatige, doeltreffende vloei en opberging van goedere, dienste en verwante inligting vanaf die plek van oorsprong tot by die plek van verbruik met die doel om aan kliëntevereistes te voldoen" (CLM 1998). Hierdie definisie verander nie die betekenis van die konsep soos verwoord in die CLM se 1991-definisie nie - die CLM voeg bloot by dat logistiek as 'n onderdeel van die voorsieningskettingproses beskou word (Lambert, Cooper en Pagh 1998: 3). Met die bekendmaking van hierdie definisie vermeld die CLM (1998; 1999: 4) ongelukkig nie wat hy met die begrip voorsieningskettingproses bedoel nie.

Die CLM se 1991-definisie van bedryfslogistiek geniet wye internasionale aanvaarding en dit word gewoonlik wêreldwyd as die ankerdefinisie aangehaal in hedendaagse bedryfslogistieke literatuur. Opmerkings oor hierdie definisie is gepas:

Eerstens, soos die definisie aandui, sluit bedryfslogistieke bestuur die handelinge in wat die vloei van goedere, dienste en inligting tussen die plek van oorsprong en plek van verbruik of aanwending (a) voorberei (beplan), (b) organiseer (implementeer) en (c) uitvoer (beheer) (Bowersox en Closs 1996: 2572; Ballou 1999: 23). Logistieke voorbereiding of beplanning sluit die keuse in van (a) vestigingsplekke (insluitende tipe, aantal, ligging en kapasiteit), (b) distribusiepartye (insluitende groothandelaars, kleinhandelaars en derdeparty-diensverskaffers) en (c) karweiers (insluitende hulpvervoer teenoor beroepsvervoer en modus) wat nodig is om die diensvlak te lewer wat kliënte verlang, ten einde die ondernemingsdoelwitte te verwesenlik. Logistieke organisasie of implementering sluit in (a) die toewysing en plasing van hulpbronne asook (b) die skedulering en uitvoering van besendings en aktiwiteite op 'n doelmatige wyse in die nastreef van die onderneming se doelwitte. Logistieke uitvoer of beheer omsluit monitering en hersiening van prestasie (soos diensgehalte, uitgawes, produktiwiteit en benutting van bates) ten einde toe te sien dat (a) die behoeftes van kliënte doeltreffend onderskraag word, (b) die onderneming se bronne doelmatig toegewys (ontplooi) word, en (c) regstellend opgetree word sodra prestasie nie in pas met doelwitbereiking is nie. 
Tweedens, aangesien logistieke bestuur gerig is op die beplanning, organisering en uitvoer van die logistieke proses, omsluit dit strategiese, taktiese en operasionele ondernemingsaktiwiteite. Op grond van Hax en Candea (1984) se bespreking van produksievoorraadstelsels, kan logistieke bedrywighede in die volgende drie vlakke verdeel word:

- Die strategiese vlak behels beplanning wat 'n langdurige invloed op die onderneming het, soos die soort, aantal, ligging, uitleg en kapasiteit van fasiliteite, sowel as die duursame toerusting wat nodig is vir die vloei van produkte en inligting deur die logistieke netwerk.

- Die taktiese vlak sluit organisatoriese aspekte in wat met tussenposes van 'n maand tot ' $n$ jaar bygewerk word. Hieronder ressorteer ook verkrygings- en vervaardigingskedules, voorraadbeleid, vervoerpraktyk en die reëlmaat waarvolgens kliënte besoek word.

- Die operasionele vlak verwys na die uitvoering van dag-tot-dag-pligte, soos roetebepaling, die skedulering van voertuie en bemanning, asook bestelprosessering.

Derdens sluit logistiek die vloei van goedere tussen die plek van oorsprong en die plek van verbruik of aanwending in. Hierdie bestek omsluit die verplasing van grondstowwe en halfvoltooide produkte vanaf primêre produsente en verkopers na vervaardiging, en die verplasing van voltooide produkte na distribusiefasiliteite en verder tot by kliënte (CLM 1986: 2). Die verskaffingsketting se oorsprong is dáár waar daar nie primêre voorsieners is nie. Alle voorsieners aan die plek van oorsprong is slegs ondersteunende leweransiers. Die plek van verbruik of aanwending is dáár waar daar nie verdere waarde toegevoeg word nie - die produk word hier verbruik of aangewend sonder om as primêre inset vir 'n volgende voorsieningsketting te dien (Porter 1984: 3).

Vierdens sluit die definisie die vloei in van goedere en dienste binne sowel die vervaardiging- as die dienstesektor (Smith et al. 1991: xvii). Die dienstesektor (of die tersiêre sektor in ekonomieterminologie) sluit in: handel, elektrisiteitsvoorsiening, vervoer, kommunikasie, onderwys en finansiële, persoonlike en openbare dienste.

Vyfdens sluit die definisie, bykomend tot die verplasing van goedere en dienste, ook inligtingvloei in (Bowersox en Closs 1996: 2572). Kliënte verwag gewoonlik dat produkte (d.i. goedere en dienste) en verwante inligting gelyktydig beskikbaar moet wees; bestel- en vragbriewe, handleidings, waarborg- en instandhoudingsinligting en fakture word byvoorbeeld gewoonlik saam met afgelewerde goedere benodig. So vind daar ook dikwels transaksie- en in transito-kommunikasie tussen 'n kliënt en 'n logistieke diensverskaffer plaas om te verseker dat 'n doeltreffende diens verskaf word.

Sesdens is die doelwit met logistieke bestuur om oor die hele stelsel heen doelmatig en doeltreffend te wees. Die oogmerk is om koste op gekoördineerde 
wyse stelselwyd te minimeer, vanaf die plasing van fasiliteite, vervoer en distribusie, tot die opberging van grondstowwe, halfvoltooide en voltooide goedere, en verpakkingskoste, telkens gedagtig aan die diensdoeltreffendheid wat kliënte vereis. Die klem is nie bloot op die goedkoopste of vinnigste vervoer of minimum voorraadvlakke nie, maar eerder op 'n geïntegreerde en gekoördineerde stelselbenadering tot die logistieke proses (Bramel en SimchiLevi 1997: 3).

Hoewel die CLM se definisie van logistiek die begrippe doelmatigheid en doeltreffendheid insluit, verwys dit nie na die versoening van die twee elemente nie. 'n Poging om koste stelselwyd te minimeer, terwyl daar ook aan kliënte se vereistes voldoen moet word, is 'n lofwaardige oogmerk, maar dit behoort binne die konteks van 'n gemeenskaplike ideaal gehanteer te word. Vanuit die onderneming se oogpunt is dié ideaal die maksimering van sy welvaart oor die lang termyn.

Logies beskou, moet die minimering van koste dus slegs daarop gerig wees om kosteverspillings uit te skakel, en nie kostebesnoeiing ten koste van groter wins nie. 'n Vermindering van logistieke koste is slegs sinvol wanneer die prysgawe van wins kleiner is as die kostebesnoeiing. Insgelyks sal die aangaan van bykomende logistieke koste, byvoorbeeld ' $n$ lugvragbesending in plaas van ' $n$ besending met ' $n$ goedkoper en stadiger vervoermodus, maar wat nie gesteun word deur 'n vermindering van voorraaddrakoste of ander logistieke kostebesparings nie, slegs geregverdig wees indien die netto inkomste as gevolg daarvan styg.

Die optimale vlak van logistieke uitgawe kom voor wanneer grenskoste (d.i. die koste van die laaste uitseteenheid) gelyk is aan grensinkomste (d.i. die inkomste wat die laaste uitseteenheid realiseer). Om hierdie aspek in ag te neem, kan bedryfslogistiek gedefinieer word as "die proses van beplanning, organisering en uitvoering van die doelmatige, doeltreffende vloei en opberging van goedere, dienste en verwante inligting, vanaf die plek van oorsprong tot by die plek van verbruik of aanwending, op so 'n wyse dat daar optimaal aan kliëntevereistes voldoen word met die doel om die welvaart van die onderneming te help maksimeer".

\section{Waardetoevoeging deur logistiek}

Vier tipes nut kan waarde tot 'n produk toevoeg, naamlik: vormnut, pleknut, tydnut en besitnut. Vormnut word geskep deur vervaardigingsaktiwiteite, pleknut en tydnut deur logistieke bedrywighede, en besitnut deur bemarkingsaksies. Vormnut ontstaan wanneer grondstowwe in 'n produksie- en/of vervaardigingsproses saamgevoeg word om 'n voltooide produk te vorm waarvoor daar 'n vraag is. Deur middel van vervoer skep logistiek pleknut deur goedere te verplaas van plekke waar hulle in onbenutbare vorm voorkom of waar daar 'n oorskot is na plekke waar hulle in benutbare vorm verwerk word of waar daar 'n vraag daarna of 'n behoefte daaraan voorkom. Logistiek skep tydnut deur 
goedere op te berg en dit later by 'n plek van aanvraag af te lewer op 'n tyd soos deur 'n kliënt verlang. Ofskoon besitnut deur produkbemarking geskep word, word dit deur logistiek ondersteun deurdat plek- en tydnut voorvereistes is om kliënte beskikkingsmag oor produkte te gee.

Elke logistieke aktiwiteit van ' $n$ onderneming kan daartoe bydra dat ' $n$ kliënt die regte produk en inligting op die aangewese plek en tyd in die vereiste toestand en hoeveelheid teen 'n aanvaarbare koste of prys ontvang. Kliëntediens is die gemeenskaplike dryfveer wat al die logistieke aktiwiteite doelgerig saambind. Die oogmerk met ' $n$ kliëntgerigte benadering is om die kliënt meer bereidwillig te maak om vir die onderneming se produkte te betaal en só die omset te stimuleer. Kliëntetevredenheid kom voor wanneer die onderneming se totale nutskepping (waardetoevoeging) sodanig is dat die kliënt geen behoefte ervaar om die produk op alternatiewe wyse te bekom nie. Optimale kliëntediens word gelewer wanneer netto inkomste per eenheid (dit is totale inkomste per eenheid minus totale koste per eenheid), vermenigvuldig met die totale aantal eenhede verkoop, 'n maksimum waarde aanneem.

\section{Gevolgtrekking}

Die woord logistiek is afgelei van die Griekse byvoeglike naamwoord logistikos, wat beteken "geskool in berekening", "met verwysing na rekenkunde" of "wat gemoeid is met rede". Die Griekse logistikos het die Europese hooftale deur die Laat-Latynse logisticus bereik wat logistique in Frans geword het. Die selfstandige naamwoord logistique het sedert 1546 begin verskyn. Die bekendstelling van die woord logistique vir die vermoë om die inkwartiering, vervoer, voorsiening en onderhoud van troepe tydens 'n militêre veldtog te kombineer en koördineer deur beredenering gegrond op berekeninge, is in 1840 deur die Franse Akademie erken.

Ná afloop van die Tweede Wêreldoorlog het die betekenis wat aan die begrip logistiek geheg is, uitgebrei na velde buite militêre verband. Sedert die vroeë jare sestig word die begrip ook in 'n bedryfskonteks gebruik. In hierdie konteks kan logistiek beskryf word as die proses van beplanning, organisering en uitvoering van die doelmatige, doeltreffende vloei en opberging van goedere, dienste en verwante inligting, vanaf die plek van oorsprong tot by die plek van verbruik of aanwending, op so ' $n$ wyse dat daar optimaal aan kliëntevereistes voldoen word met die doel om die welvaart van die onderneming te help maksimeer.

In gewone omgangstaal is logistiek die gedetailleerde beplanning, organisering en uitvoering van 'n ingewikkelde operasie wat die toewysing en verspreiding van middele behels.

Ongeag of die woord in 'n militêre of bedryfsverband, of in alledaagse situasies gebruik word, is die doel van logistiek om toe te sien dat die regte produkte (d.i. goedere en dienste) en inligting op die aangewese plek en tyd in die vereiste toestand en hoeveelheid teen 'n aanvaarbare koste of prys beskikbaar gestel word. 


\section{Verwysings}

\section{Woordeboeke en ensiklopedieë}

Baale, L.M. en C.H. Baale. s.j. Handboek van Vreemde Woorden, Uitdrukkingen enz. Zutphen: W.T. Thieme.

Bowersox, D.J. en D.J. Closs. 1996. Logistics. International Encyclopedia of Business and Management. Volume 3. Londen: Routledge.

Buro van die WAT. 1994. Woordeboek van die Afrikaanse Taal. Deel 9. Stellenbosch.

Cambridge University Press. 1995. Cambridge International Dictionary of English. Cambridge.

Dictionnaires Le Robert. 1976. Petit Robert: Dictionnaire Alphabétique et Analogique de la Langue Français. Parys.

Dictionnaires Le Robert. 1996. Petit Robert: Dictionnaire Alphabétique et Analogique de la Langue Français. Parys.

Hinkelman, E.G. 20004. Dictionary of International Trade: Handbook of the Global Trade Community. Novato, Kalifornië: World Trade Press.

Macksey, K. en W. Woodhouse. 1991. The Penguin Encyclopedia of Modern Warfare: 1850 to the Present Day. Londen: Viking.

Odendal, F.F. (Red.). 1994³. Verklarende Handwoordeboek van die Afrikaanse Taal. Midrand: Perskor.

Oxford University Press. 1993. Oxford Dictionary for the Business World. Oxford.

Parkinson, R. 1977. Encyclopedia of Modern War. Londen: Routledge.

Statt, D.A. 1991. The Concise Dictionary of Management. Londen: Routledge.

Van Dale Lexicografie. 1984⒈ Van Dale Groot Woordenboek der Nederlandse Taal. Tweede deel J-R. Utrecht/Antwerpen.

Van Veen, P.A.F. en N. van der Sijs. 1997. Etymologisch Woordenboek: De herkomst van onze woorden. Utrecht/Antwerpen: Van Dale Lexicografie.

\section{Ander bronne}

Ballou, R.H. 19872. Basic Business Logistics, Transportation, Materials Management, and Physical Distribution. Englewood Cliffs, N.J.: Prentice-Hall.

Ballou, R.H. 1999. Business Logistics Management. Englewood Cliffs, N.J.: Prentice-Hall.

Boucher, C. 1998. Logistique. Private faksimileekommunikasie ontvang van professor Claude Boucher, Universiteit van Sherbrooke, Kanada, oor die etimologie van die woord logistique in die Franse taal. (Faksimileekopie in besit van die skrywer.) Montreal.

Bramel, J. en D. Simchi-Levi. 1997. The Logic of Logistics: Theory, Algorithms, and Applications for Logistics Management. New York: Springer.

Council of Logistics Management. 1986. What It's All About. Oak Brook, Illinois.

Council of Logistics Management. 1991. What It's All About. Oak Brook, Illinois.

Council of Logistics Management. 1998. www.CLM1.org.

Council of Logistics Management. 1999. What It's All About. Oak Brook, Illinois.

Hax, A.C. en D. Candea. 1984. Production and Inventory Management. Englewood Cliffs, N.J.: Prentice-Hall. 
Lambert, D.M., M.C. Cooper en J.D. Pagh. 1998. Supply Chain Management: Implementation Issues and Research Opportunities. The International Journal of Logistics Management 9(2): 1-18.

Plowman, E.G. 1964. Lectures on Elements of Business Logistics. Palo Alto, Kalifornië: Graduate School of Business, Stanforduniversiteit.

Porter, M.E. 1984. Competitive Advantage - Creating and Sustaining Superior Performance. New York: The Free Press.

Ruppenthal, K.M. (Red.). 1963. New Dimensions in Business Logistics. Proceedings of the First Annual Business Logistics Forum, 1962. Palo Alto, Kalifornië: Graduate School of Business, Stanforduniversiteit.

Smith, P.A., J. Barry, J.L. Cavinato, J.J. Coyle, S.J. Dunn en W. Grenoble. 1991. Logistics in Service Industries. Oak Brook, Illinois: Council of Logistics Management.

Smykay, E.W., D.J. Bowersox en F.H. Mossman. 1961. Physical Distribution Management: Logistics Problems of the Firm. New York: Macmillan. 